\title{
Pierre Bourdieu e Paulo Freire: um diálogo pela Educação
}

\begin{abstract}
RESUMO: A realidade da educação brasileira atualmente demonstra que existe uma variedade de práticas educativas colocadas em ação nas escolas, tais elas que seriam um reflexo das várias teorias já publicadas e experimentadas ao longo dos estudos pedagógicos. Pierre Bourdieu, em sua teoria, demonstrou que os sistemas de ensino atuariam como mecanismos de reprodução e legitimação das desigualdades sociais. Paulo Freire, ao construir sua teoria sobre a educação, constatou que a realidade da sociedade se apresentaria na forma de opressão dos povos, elaborando um método de educação para a libertação dos oprimidos. Nesse sentido, o objetivo deste ensaio foi compreender a teoria crítico-reprodutivista de Pierre Bourdieu e a teoria crítica de Paulo Freire, a fim de que se pensasse de que forma o diálogo entre ambas poderia contribuir com as práticas educativas. A metodologia ocorreu por meio da revisão de literatura sobre essas teorias, e da análise das informações observadas a partir delas. Trata-se, assim, de um estudo bibliográfico de objeto qualitativo. As análises do ensaio observaram que a escola atuaria como um meio de reprodução e legitimação das desigualdades sociais, e que, ao se impor sobre os estudantes, ela agiria como um mecanismo próprio das sociedades opressoras. Nessa perspectiva, a correlação entre os fundamentos teóricos dos dois autores revelou que é preciso romper com as práticas educativas tradicionais e não críticas, as quais reforçam e, desse modo, atuam para a manutenção da sociedade desigual tal qual ela se apresenta.
\end{abstract}

Palavras-chave: Desigualdades sociais. Pedagogia Libertadora. Sociedade e Educação.
Jhonathas Armond Assis Ramos Universidade Federal de São João del-Rei (UFSJ)

jhonathas.armond@gmail.com

\section{Introdução}

Vivências no ambiente escolar brasileiro do século XXI podem demonstrar que as práticas educativas presentes nas escolas refletem as várias teorias já produzidas e experienciadas, em períodos específicos da história do pensamento pedagógico, havendo, muitas vezes, uma mistura de aplicações dessas diferentes concepções de educação, que, em alguns casos, são, inclusive, conflitantes entre si. Um dos motivos para a observação dessa realidade talvez fosse a descontinuidade das políticas educacionais no país, relacionadas a essas diferentes teorias, as quais, alteradas constantemente, mal chegam a ser executadas a tempo de apresentarem resultados suficientes de avaliação dessas alterações. Outra razão poderia ser relacionada ao fato de que, até mesmo influenciada pela primeira causa apontada, diferentes educadores nas diferentes escolas, ao trabalharem os diferentes conteúdos do currículo escolar, utilizam 
práticas que diferem de caso para caso em circunstância da realidade de cada contexto.

Essa complexa realidade da educação brasileira, no que se refere às diferentes teorias do conhecimento pedagógico colocadas em prática, pode se apresentar como favorável, caso se utiliza o que é válido em cada uma delas, mas também apresenta deficiências, uma vez que algumas, as mais tradicionais, não promovem o pensamento crítico dos educandos ou até mesmo dos educadores quanto a sua prática em sala de aula. Aliás, as teorias que se opõem às práticas de uma pedagogia não crítica revelam, inclusive, como aponta Suhr (2012, p. 121), "o caráter subordinado da educação, mostrando que ela não é neutra, muito pelo contrário: ela cumpre um papel importante na manutenção da sociedade capitalista". Nesse sentido, as chamadas teorias crítico-reprodutivistas, as quais compreendem que a educação está intimamente ligada aos condicionantes sociais, reconhecem que a escola está submissa aos interesses das camadas dominantes, e, consequentemente, é uma forma de discriminação social, reproduzindo a dominação e a marginalização dos meios menos favorecidos.

Em concordância às teorias crítico-reprodutivistas, apesar de reconhecerem o caráter da escola de reprodução e manutenção das desigualdades sociais, as teorias críticas ou progressistas propõem mudanças nessa estrutura, acreditando na educação como agente de transformação da realidade. "São, portanto, teorias que, embora compreendam o caráter condicionado da escola, colocam-na como possibilidade de favorecer a transformação social". (SUHR, 2012, p. 138)

Pierre Bourdieu foi um dos principais teóricos a pensar a educação como elemento reforçador das desigualdades sociais. Paulo Freire, reconhecendo esse caráter da escola, propôs uma educação problematizadora e dialógica, voltada para o desenvolvimento da autonomia e modificação da realidade. Assim sendo, que contribuição um diálogo entre a teoria crítico-reprodutivista de Bourdieu e a teoria crítica de Freire poderia trazer para as práticas educativas? Logo, o objetivo geral deste trabalho foi correlacionar os fundamentos teóricos de Bourdieu e Freire sobre a educação para se pensar em que sentido esse diálogo poderia contribuir com as práticas educativas. Os objetivos específicos foram: compreender alguns dos principais apontamentos teóricos de Bourdieu sobre o sistema de ensino em relação às sociedades de classes; e conhecer 
algumas das considerações teóricas mais importantes da educação libertadora de Freire.

Este estudo se faz relevante por trazer reflexões e estabelecer correspondências entre as teorias de dois grandes pensadores da educação em relação a seu papel na sociedade. Sobretudo, ao estabelecer esse diálogo entre Bourdieu e Freire, este ensaio contribui com o avanço do entendimento e da importância de práticas educativas críticas.

Após a Introdução, a primeira seção deste ensaio apresenta a metodologia utilizada na construção deste estudo. A segunda seção explicita as principais teorias desenvolvidas por Bourdieu sobre a escola e sua relação com as desigualdades das sociedades de classes. A terceira seção expressa as ideias fundamentais produzidas por Freire no que se refere à pedagogia que ele chamou de educação libertadora. E a quarta seção deste estudo evidencia as possíveis relações entre as teorias dos dois autores, e a contribuição desse diálogo para se pensar as práticas educativas.

\section{Metodologia}

A fim de se atingir os objetivos propostos neste ensaio, o presente texto fez uso de revisão de literatura sobre o que Bourdieu produziu de mais importante no que diz respeito à relação dos sistemas de ensino com a reprodução das desigualdades sociais, assim como sobre as obras de Freire que trouxessem como se apresentava a educação problematizadora e libertadora elaborada por ele. Construiu-se, assim, o aparato teórico, por meio do qual foi possível conhecer e sintetizar as principais teorias de ambos os autores.

Em seguida, analisaram-se as respectivas teorias de Bourdieu e Freire, estabelecendo uma relação teórica entre elas que fosse ao encontro do objetivo geral deste estudo, e, consequentemente, da resposta ao questionamento que regeu este ensaio.

A revisão de literatura é um pré-requisito necessário à realização de qualquer pesquisa, sendo ela bibliográfica ou empírica. No caso de uma pesquisa bibliográfica, como argumentam Lima e Mioto (2007), é necessário fundamentar o objeto de estudo teoricamente, contribuindo com elementos que vão subsidiar a análise das informações, indo além de sua simples observação. Deve-se atentar para esses elementos porque, nesse tipo de estudo, é mister 
que se faça uma compreensão crítica do significado existente nas informações observadas.

Portanto, este é um estudo que, fazendo uso das técnicas de revisão de literatura e análise das informações observadas, caracteriza-se como bibliográfico, cujo objeto, como afirmam Lima e Mioto (2007), é essencialmente qualitativo.

\section{A teoria crítico-reprodutivista de Pierre Bourdieu: a escola como meio de reprodução cultural e conservação social}

Pierre Bourdieu (Denguin, 1930 - Paris, 2002) foi um grande pensador francês do século XX, considerado um renovador da Sociologia. Tendo publicado mais de 300 títulos, somando-se livros e artigos, tornou-se autor frequente em diversos campos disciplinares, tais como Antropologia, Economia, Educação, História e Sociologia. Em sua extensa e rigorosa obra, concebida por meio de objetos empíricos diversificados, foi capaz de construir conceitos próprios do mundo sociológico, elucidando, por exemplo, as funções sociais dos sistemas de ensino, práticas de distinção cultural, e formas dissimuladas de dominação e exercício do poder. (NOGUEIRA, M.; NOGUEIRA, C., 2016) Segundo Nogueira, M. e Nogueira, C. (2016, p. 11),

Bourdieu teve o mérito de formular, a partir dos anos 60, uma resposta original, abrangente e bem fundamentada, teórica e empiricamente, para o problema das desigualdades escolares. Essa resposta tornou-se um marco na história, não apenas da Sociologia da Educação, mas do pensamento e da prática educacional em todo o mundo.

Antes dessa formulação, pensava-se que a escola pública e gratuita resolveria tanto o problema da falta de acesso à educação quanto o da desigualdade de oportunidades, ou seja, por intermédio da escola, os sujeitos poderiam competir em condições de igualdade dentro do sistema de ensino; aqueles cujo desempenho, por seus dons individuais, tivesse destaque, pela lógica de justiça, avançariam em suas carreiras escolares e, consequentemente, ocupariam posições mais elevadas na hierarquia social. Tratava-se, portanto, de uma percepção da escola como sendo uma instituição neutra. Nos anos 1960, entretanto, esse otimismo em relação à concepção 
de escola passou por uma crise, havendo uma reinterpretação da função dos sistemas de ensino. O desempenho escolar passou a ser visto como atrelado à origem social dos estudantes, como classe, etnia, local de moradia, e sexo, por exemplo. (NOGUEIRA, M.; NOGUEIRA, C., 2016) Notadamente, estudantes de condições sociais menos favorecidas tenderiam a não avançar tanto em suas carreiras escolares, e, assim, a se manter em posições socias mais baixas que aqueles de camadas sociais privilegiadas, com melhores condições, portanto, de se destacar em seu percurso escolar.

A forte relação entre a origem social e o desempenho escolar levaram Bourdieu a propor suas teorias que mostravam que os sistemas de ensino, além de não serem, como se pensava, agentes transformadores e democratizadores das sociedades, seriam, ao contrário, um meio de reprodução e legitimação das desigualdades já vistas fora da escola. (NOGUEIRA, M.; NOGUEIRA, C., 2016) Disso, pode-se, então, questionar: de que maneira a escola promoveria essa reprodução e essa legitimação das desigualdades sociais?

Para compreender essa relação entre os sistemas de ensino e a reprodução e legitimação de privilégios sociais, é preciso, antes, esclarecer que, para Bourdieu, os indivíduos teriam incorporado um habitus familiar ou de classe, o qual os conduziria no tempo e nos diferentes ambientes de ação. Para o autor, o habitus seria:

[...] uma noção mediadora que ajuda a romper com a dualidade de senso comum entre indivíduo e sociedade ao captar "a interiorização da exterioridade e a exteriorização da interioridade", ou seja, o modo como a sociedade se torna depositada nas pessoas sob a forma de disposições duráveis, ou capacidades treinadas e propensões estruturadas para pensar, sentir e agir de modos determinados, que então as guiam nas suas respostas criativas aos constrangimentos e solicitações do seu meio social existente. (WACQUANT, 2017, p. 214, grifos do autor)

Assim, como afirmam Nogueira, M. e Nogueira, C. (2016), os indivíduos não poderiam ser vistos isoladamente, conscientes e reflexivos, tampouco como sujeitos condicionados e mecanicamente submetidos às condições exteriores em que estão contextualizados. Eles seriam formados pelo patrimônio herdado socialmente, que inclui aspectos objetivos, isto é, externos a eles, mas também aspectos subjetivos que passam a fazer parte de sua individualidade. 
Os primeiros seriam caracterizados pelo capital econômico, capital social e capital cultural institucionalizado, os quais, em conjunto, poderiam ser colocados a serviço do sucesso escolar. Já os últimos seriam definidos pelo capital cultural incorporado.

O capital econômico pode ser entendido, sobretudo, como os bens e serviços aos quais os recursos financeiros dão acesso. O capital social, para Bourdieu, seria determinado pela manutenção, por parte das famílias, de certo conjunto de relações sociais influentes ou, como ele mesmo define:

[...] é o conjunto de recursos atuais ou potenciais que estão ligados à posse de uma rede durável de relações mais ou menos institucionalizadas de interconhecimento e de interreconhecimento ou, em outros termos, à vinculação a um grupo, como conjunto de agentes que não somente são dotados de propriedades comuns (passíveis de serem percebidas pelo observador, pelos outros ou por eles mesmos), mas também são unidos por ligações permanentes e úteis. (BOURDIEU, 2015b, p. 75 , grifo do autor)

O capital cultural, segundo Bourdieu (2015c), existiria sob três estados ou formas: incorporado, objetivado e institucionalizado. O estado incorporado seria a forma fundamental do capital cultural, significando um trabalho pessoal de inculcação e assimilação de propriedades a serem investidas, cultivadas, pelo sujeito, a fim de efetuar uma incorporação propriamente dita desses elementos, o que custaria tempo, manifestando-se esse estado como uma parte integrante do próprio indivíduo. Alguns exemplos de capital cultural incorporado seriam os gostos manifestos pelo sujeito em relação a arte, decoração, esportes, gastronomia, música, vestuário ou o maior ou menor domínio da norma culta da língua ou, ainda, informações sobre a estrutura e o funcionamento da escola. "O capital cultural é um ter que se tornou ser, uma propriedade que se fez corpo e tornou-se parte integrante da 'pessoa', um habitus". (BOURDIEU, 2015c, p. 83, grifo do autor) O estado objetivado do capital cultural possuiria propriedades que somente o definem à medida que estas estabelecessem relação com o capital cultural incorporado, pois, ao estar objetivado em suportes materiais, o capital cultural, se não transmitido em sua condição de apropriação específica desses suportes, somente configuraria a transmissão de sua materialidade, tal como o capital econômico, por exemplo. 
Assim, os bens culturais podem ser objeto de uma apropriação material, que pressupõe o capital econômico, e de uma apropriação simbólica, que pressupõe o capital cultural. Por consequência, o proprietário dos instrumentos de produção deve encontrar meios para se apropriar ou do capital incorporado que é a condição da apropriação específica, ou dos serviços dos detentores desse capital. (BOURDIEU, 2015c, p. 85)

Dicionários, instrumentos, livros, máquinas e quadros seriam exemplos desse estado do capital cultural, por meio dos quais e para os quais é possível que se estabeleçam indícios ou a própria produção de teorias ou críticas de pressupostos para um conjunto de questões. Por fim, o capital cultural em seu estado institucionalizado seria o capital cultural com reconhecimento institucional, o qual é capaz de garantir ao seu possuidor características próprias, convencionais e constantes, além de juridicamente garantidas, o caso dos diplomas e certificados escolares.

Juntos, o capital econômico, o capital social e o capital cultural institucionalizado definiriam, portanto, os componentes objetivos, externos, ao indivíduo. Já o capital cultural incorporado determinaria os componentes subjetivos, internos, que caracterizam os sujeitos.

Principalmente em seu estado incorporado, e considerado por Bourdieu como o aspecto de maior relevância na definição do destino escolar, o capital cultural favoreceria o desempenho escolar dos sujeitos que o possuem. Primeiramente porque aqueles conhecimentos considerados cultos e apropriados trazidos por certas crianças, além do maior domínio da língua culta, ao funcionarem como uma conexão entre o âmbito familiar desses sujeitos e a escola, agiriam de maneira a facilitar o aprendizado escolar, no sentido de que a educação escolar seria uma continuação da educação familiar para as crianças provenientes de estratos culturalmente beneficiadas, ao contrário daquelas advindas dos meios populares, para as quais a educação escolar seria um mundo estranho e distante, quando não, até mesmo, ameaçador. Em segundo lugar porque a avaliação escolar exigiria, por meio de um julgamento cultural e moral, que os estudantes apresentassem determinados comportamentos e habilidades, tais como curiosidade e interesse intelectual, escrita e fala elegantes, disciplina, algo que apenas seria plenamente respondido por aqueles que já são educados e socializados em casa nos mesmos tipos de valores, portanto. Uma terceira razão seria que o conhecimento dos sistemas de ensino, 
principalmente no que diz respeito à compreensão das distintas ramificações escolares, atentando-se à qualidade acadêmica, ao prestígio social e ao retorno financeiro, é primordial aos pais no estabelecimento e empreendimento de estratégias eficazes para a orientação da trajetória escolar dos filhos. (NOGUEIRA, M.; NOGUEIRA, C., 2016)

Para Bourdieu (2015a), como cada família transmite aos filhos, sobretudo por mecanismos indiretos, certo capital cultural, assim como determinados valores implícitos e fortemente interiorizados - sistema que o autor denomina ethos -, o patrimônio cultural desses indivíduos, principalmente em determinação de sua origem social, difere em atitudes frente à cultura do sistema de ensino. Essas distintas bagagens culturais se tornariam, na escola, tanto a distância inicial das crianças em sua experiência escolar quanto, e em consequência, as diferentes taxas de êxito por elas obtidas.

Diferentemente das crianças oriundas das classes populares, que são duplamente prejudicadas no que respeita à facilidade de assimilar a cultura e a propensão para adquiri-la, as crianças das classes médias devem à sua família não só os encorajamentos e exortações ao esforço escolar, mas também um ethos de ascensão social e de aspiração ao êxito na escola e pela escola, que lhes permite compensar a privação cultural com a aspiração fervorosa à aquisição de cultura. (BOURDIEU, 2015a, p. 53)

Percebe-se, portanto, como o capital cultural determinaria um maior peso que o capital econômico para a explicação das desigualdades escolares, o que, de acordo com Nogueira, M. e Nogueira, C. (2016), seria justamente o fato que notabiliza a Sociologia da Educação de Bourdieu. Conforme esses autores, inclusive, tanto o capital econômico quanto o capital social seriam instrumentos auxiliares de acumulação do capital cultural, como, por exemplo, o contato pessoal com amigos e parentes familiarizados com o sistema escolar, e o acesso a viagens de estudo, respectivamente.

Caracterizados, assim, por esse conjunto de fatores interiorizados e externos, os indivíduos, para Bourdieu, carregariam heranças culturais e sociais distintas e mais ou menos vantajosas ao adentrarem a escola. Logo, eles não estariam, ao contrário do que se afirmava antes dos anos 1960, em condições de competir igualitariamente nos sistemas de ensino, pois, como demonstrado, sua origem social determinaria fortemente as condições de seu 
maior ou menor favorecimento em relação às exigências colocadas pela escola, instituição que, ao ignorar as desigualdades culturais entre as crianças de distintas camadas sociais, diferenciaria os mais abastados por meio de critérios objetivos.

A escola não seria uma instância neutra que transmitiria uma forma de conhecimento intrinsecamente superior às outras formas de conhecimento, e que avaliaria os alunos com base em critérios universalistas; mas, ao contrário, ela é concebida como uma instituição a serviço da reprodução e da legitimação da dominação exercida pelas classes dominantes. (NOGUEIRA, M.; NOGUEIRA, C., 2016, p. 71)

Segundo a concepção bourdiesiana, nenhuma cultura poderia ser considerada superior às demais. O que ocorre em relação à cultura escolar, no entanto, é que, por ser socialmente reconhecida como a única válida universalmente, ela seria a cultura, então, imposta como legítima pelas classes dominantes, as quais possuem a capacidade de sustentá-la e impô-la devido à força de dominação que têm nas sociedades de classes. Todavia, a legitimidade dos sistemas de ensino somente se sustentaria porque a cultura escolar é apresentada como sendo neutra, ou seja, como não atrelada a nenhuma classe social, ocultando, assim, o processo de imposição dissimulada de determinada cultura, o qual é chamado por Bourdieu de "violência simbólica". É nesse sentido que a escola, admitida como portadora de uma cultura universal e neutra, reproduziria e legitimaria as desigualdades sociais. (NOGUEIRA, M.; NOGUEIRA, C., 2016)

A reprodução seria garantida pelo simples fato de que os alunos que dominam, por sua origem, os códigos necessários à decodificação e assimilação da cultura escolar e que, em função disso, tenderiam a alcançar o êxito escolar, seriam aqueles pertencentes às classes dominantes. A legitimação das desigualdades sociais ocorreria, por sua vez, indiretamente, pela negação do privilégio cultural oferecido - camufladamente - aos filhos das classes dominantes. (NOGUEIRA, M.; NOGUEIRA, C., 2016, p. 75)

Para Bourdieu, o pior impacto da violência simbólica exercida pela escola sobre os estudantes provenientes dos meios sociais menos favorecidos seria a desvalorização de sua cultura familiar, ao 
inculcar nesses indivíduos a ideia de superioridade e legitimidade da cultura dominante. Além disso, ao promover, mesmo que informalmente, avaliações dos estudantes com base em comportamentos e habilidades culturalmente valorizados, a escola interpretaria essas aptidões como manifestações inatas, reforçando suas funções de reprodução e legitimação das desigualdades, pois, como já visto, esses seriam saberes que, em grande parte, somente seriam adquiridos pelos filhos dos meios mais favorecidos culturalmente.

Uma vez que forneceria a aparência de legitimidade a essas desigualdades, e admitiria a herança cultural e o dom social como dom natural dos sujeitos, o sistema escolar seria um dos meios eficazes de preservação social. (BOURDIEU, 2015a) Com efeito, porque todos teriam as mesmas oportunidades de alcançar o sucesso no mundo escolar, a escola, dissimuladamente apresentada como democrática, justificaria, por meio do fracasso individual, a permanência dos sujeitos em suas posições sociais menos favorecidas, pois os sistemas de ensino encarariam que as carreiras escolares não exitosas seriam resultado da falta de empenho dos indivíduos, da ausência do dom natural individual para os estudos, ignorando sua herança cultural. (NOGUEIRA, M.; NOGUEIRA, C., 2016) “Em outras palavras, tratando todos os educandos, por mais desiguais que sejam eles de fato, como iguais em direitos e deveres, o sistema escolar é levado a dar sua sanção às desigualdades iniciais diante da cultura". (BOURDIEU, 2015a, p. 59)

Em 1964, Bourdieu chegou a imaginar uma solução para a perversidade da manutenção dos privilégios culturais a partir da escola, o que ele chamou de "pedagogia racional" ou "racionalização da pedagogia". O princípio dessa ideia seria tornar explícito tudo o que os sistemas escolares fazem implicitamente em seu funcionamento, a fim de realizar uma ação pedagógica por meio de uma aprendizagem "metódica" e contínua, capaz de neutralizar os aspectos sociais de desigualdade cultural. O autor, todavia, seis anos depois, convenceu-se de que um trabalho nesse sentido não passaria de uma utopia, encarando que o processo de reprodução das estruturas sociais pela escola dificilmente seria evitado, sobretudo porque as oportunidades de acesso e sucesso das camadas populares e médias na educação seriam acompanhadas por modificações qualitativas e quantitativas no processo de escolarização das elites, mantendo sua distinção social por meio instituições, níveis ou ramos de ensino mais raros e, portanto, mais valorizados 
socialmente, processo a que Bourdieu deu o nome de "translação global das distâncias". (NOGUEIRA, M.; NOGUEIRA, C., 2016)

\section{A teoria crítica de Paulo Freire: a educação como ato político e meio de transformação social}

Paulo Freire (Recife, 1921 - São Paulo, 1997) foi um dos mais renomados intelectuais brasileiros do século XX, sendo reconhecido em todo o mundo por contribuir enormemente no campo teórico e prático da Educação. Ao elaborar uma teoria crítica e política a respeito da realidade educacional, o autor dedicou-se profundamente à ideia do diálogo como possibilidade de conscientização dos sujeitos para a transformação social, política e econômica da realidade injusta em que se encontram. (FREIRE, 2018)

A obra de Freire é, marcadamente, envolvida pela busca da superação de uma realidade social que ele dizia ser opressora e que, objetiva tal como ela é, não existiria por acaso nem se transformaria sozinha, sem a ação humana. Ao se configurar assim, ela implicaria a existência daqueles que oprimem e daqueles que são oprimidos. A libertação dos oprimidos somente se daria a partir de sua conscientização dessa realidade, acompanhada de uma "práxis" - ação e reflexão sobre o mundo para sua transformação - voltada para esse sentido. (FREIRE, 2018) Tarefa esta que, para ele, não seria tranquilamente realizada, o que não a tornaria impossível, mas porque o processo de opressão existente seria um problema não apenas à libertação humana, mas um problema que se impunha como um mecanismo de absorção, imersão das consciências, sendo, nesse sentido, uma realidade domesticadora e, por isso, a libertação dela somente se daria por meio da práxis autêntica, capaz de emergir das forças opressoras.

Na busca dessa ação e reflexão autêntica, conscientizadora, a que Freire chamou de "pedagogia do oprimido", haveria dois momentos distintos:

O primeiro, em que os oprimidos vão desvelando o mundo da opressão e vão comprometendo-se, na práxis, com a sua transformação; o segundo, em que, transformada a realidade opressora, esta pedagogia deixa de ser do oprimido e passa a ser a pedagogia dos homens em processo de permanente libertação. (FREIRE, 2018, p. 57) 
Tanto em um quanto em outro momento, seria essa ação profunda que, culturalmente, enfrentaria a cultura da dominação, a chamada "revolução cultural". Primeiramente, pela conscientização da existência da realidade opressora. Depois, por meio da expulsão dos mitos que essa mesma realidade desenvolveria. (FREIRE, 2018)

Para Freire (2018), a violência dos que oprimem proibiria os oprimidos de "ser", e a resposta destes que sofrem a opressão deveria se dar pelo desejo de busca do "direito de ser". E, nessa proibição e violência, características do processo de opressão, os próprios opressores não poderiam, também eles, "ser". Isso porque, ao oprimir e esmagar, eles teriam perdido sua humanidade, que somente se restauraria a partir da retirada, pelos oprimidos, do seu poder de oprimir.

A educação, como reflexo das estruturas opressoras do poder, seria uma maneira de apassivar, ainda mais, o ser humano, de adaptá-lo ao mundo. Freire afirmava que a educação nas escolas se apresentava por meio de relações que seriam fundamentalmente narradoras, dissertadoras, conduzindo o educando à memorização. Em vez de se comunicar, o educador o que fazia eram "comunicados" e "depósitos", que os educandos recebiam, memorizavam e repetiam, colecionando e arquivando coisas, portanto, impedidos de "ser". Era o que ele chamava de concepção "bancária" da educação. Um processo dos que se julgavam saber sobre os que nada saberiam, manifestação ideológica da opressão. Alienação da ignorância, essa visão "bancária" manteria o educador em posições fixas, negando a educação e o conhecimento como procedimentos de busca. Reconhecendo sua ignorância como a razão de ser do educador, os educandos se manteriam alienados. A educação que deveria se fazer libertadora, inicialmente, agiria nesse ponto, implicando a superação da contradição que havia entre educadores e educandos da concepção "bancária", reflexo da sociedade opressora, dimensão da "cultura do silêncio". Ambos deveriam, na educação libertadora, fazer-se, ao mesmo tempo, educadores e educandos. (FREIRE, 2018)

Para Freire (2018), o diálogo seria a maneira autêntica de libertação, pois somente ele implicaria um pensar crítico, e somente por meio dele haveria verdadeira educação. Portanto, o diálogo operaria na contradição educador-educando.

Apesar da dificuldade de atuar numa estrutura que negaria o diálogo, uma vez que a educação, ao refletir a estrutura do poder, 
coerentemente agiria em prol do silêncio, Freire (2018) afirmava que o educador humanista, na concepção problematizadora e libertadora da educação, deveria dialogar sobre a negação do diálogo existente na sociedade, a fim de que sua ação se identificasse com a ação dos educandos. Nesse sentido, essa ação dos educadores deveria se orientar pela humanização, pelo pensar autêntico, pela crença no ser humano e em seu poder criador, exigindo que eles fossem companheiros dos educandos.

O que nos parece indiscutível é que, se pretendemos a libertação dos homens, não podemos começar por aliená-los ou mantêlos alienados. A libertação autêntica, que é a humanização em processo, não é uma coisa que se deposita nos homens. Não é uma palavra a mais, oca, mitificante. É práxis, que implica a ação e a reflexão dos homens sobre o mundo para transformá1o. (FREIRE, 2018, p. 93, grifo do autor)

Para o educador compromissado com a libertação dos educandos, portanto, um educador-educando, o conteúdo programático da educação dialógica, problematizadora, deveria ser "a devolução organizada, sistematizada e acrescentada ao povo daqueles elementos que este lhe entregou de forma desestruturada". (FREIRE, 2018, p. 116) Seria preciso acreditar no povo, e aprender com as bases populares por meio da troca de conhecimentos, processo pelo qual se daria um aprendizado sério e autêntico para as pessoas que delas fazem parte. A educação deveria, nesse sentido, identificar-se com as condições da realidade dos sujeitos. Segundo Freire (1967), seria preciso pensar em métodos ativos de educação, que criticizassem os indivíduos, e promovessem o debate de situações desafiadoras e existenciais para os educandos.

Nesse sentido, Freire (2018) criou o diálogo necessário à "educação como prática da liberdade" por meio da investigação do que ele chamava de "universo temático" ou "temas geradores" do povo. Tratava-se de uma investigação problematizadora de conhecimentos trazidos do contexto vivido pelas pessoas. Colocados em interação entre si, esses temas possibilitariam sua apreensão e uma forma crítica de pensar a realidade, pois somente seriam entendidos nas relações que se estabelecem entre o ser humano e o mundo. Por partir da visão de mundo dos educandos, o conteúdo estaria, constantemente, renovando-se e se ampliando. 
Em relação à alfabetização, a educação problematizadora proposta seria a partir da "palavra geradora". (FREIRE, 2018) A própria alfabetização, na visão de Freire (1967), seria o domínio de técnicas, sim, de ler e escrever, mas, principalmente, o entendimento consciente do que se lê e do que se escreve. Um modo de interferência do meio, em uma atitude de criação e recriação. Leitura da palavra e leitura do mundo.

\begin{abstract}
Numa visão libertadora, não mais 'bancária' da educação, o seu conteúdo programático já não involucra finalidades a serem impostas ao povo, mas, pelo contrário, porque parte e nasce dele, em diálogo com os educadores, reflete seus anseios e esperanças. Daí a investigação da temática como ponto de partida do processo educativo, como ponto de partida de sua dialogicidade. (FREIRE, 2018, p. 143, grifo do autor)
\end{abstract}

A dialogicidade da concepção problematizadora da educação proposta por Freire seria a base autêntica da conscientização dos educandos em relação a sua realidade. Possibilitando, portanto, uma visão da realidade de maneira crítica, a educação, transformada pelo diálogo, proporcionaria as condições autênticas também de libertação dos oprimidos. Seria, assim, "[...] uma educação para a decisão, para a responsabilidade social e política”. (FREIRE, 1967, p. 88)

A educação, em sua concepção libertadora promoveria, então, a transformação das estruturas opressoras da sociedade, na medida em que os oprimidos tomassem consciência crítica de seu papel social e político, pois, segundo Freire (1967, p. 90, grifos do autor), essa educação seria:

\footnotetext{
Uma educação que possibilitasse ao homem a discussão corajosa de sua problemática. De sua inserção nesta problemática. Que o advertisse dos perigos de seu tempo, para que, consciente deles, ganhasse a força e a coragem de lutar, ao invés de ser levado e arrastado à perdição de seu próprio 'eu', submetido às prescrições alheias. Educação que o colocasse em diálogo constante com o outro. Que o predispusesse a constantes revisões. À análise crítica de seus 'achados'. A uma certa rebeldia, no sentido mais humano da expressão. Que o identificasse com métodos e processos científicos.
}

Freire (1967, p. 92) dizia que seria necessário ajudar os brasileiros "a aprender democracia, com a própria existência desta". 
Nessa perspectiva, por meio de uma educação que se fizesse autenticamente democrática, isto é, com a participação de todos os evolvidos nos processos educativos, de forma dialógica entre educadores e educandos, os sujeitos se entenderiam como os seres políticos que são, e poderiam, consequentemente, exercer seu papel na sociedade de forma crítica, na busca de transformações sociais justas para todos.

\section{O diálogo entre Bourdieu e Freire}

Realizar um possível diálogo entre as teorias sobre a educação de Bourdieu e Freire não seria uma tarefa tão simples, dada a complexidade e extensão das obras de cada autor. De um lado, tem-se uma das bases teóricas das teorias crítico-reprodutivistas da escola observando e revelando sua falsa neutralidade e consequentes funções de reprodução da cultura legitimamente reconhecida, e de manutenção das desigualdades sociais. De outro lado, um dos fundamentos das teorias críticas da educação revelando a estrutura opressora da sociedade, mas propondo, então, uma pedagogia que fosse de encontro a essa opressão.

As teorias, tanto de Bourdieu quanto de Freire, críticas que se fizeram do papel da escola na sociedade, reconheciam a inércia das instituições escolares acerca de uma possível superação das injustiças sociais. Nesse sentido, por mais desafiador que pudesse ser, estabelecer relações entre os dois teóricos poderia surtir resultados positivos em termos do reconhecimento dos papéis da escola na sociedade, e, em consequência, da contribuição que esse reconhecimento poderia trazer para a questão de como se apresentam as práticas educativas.

O primeiro ponto, que pode ser analisado em relação às teorias de Bourdieu e Freire sobre a educação, diz respeito ao modelo de sociedade em que essa educação se dá. Trata-se, nos dois casos, de análises realizadas pelos autores da escola/educação nas sociedades divididas em camadas sociais. Nessas sociedades, predominam as manifestações das mais explícitas às mais implícitas de diferenças sociais enormes. Essas diferenças se dariam pelo efeito produzido de umas classes em relação às outras no acesso e controle a bens sociais comuns, e, sobretudo, pelo controle do poder pelas elites. Em Bourdieu, esse controle seria obtido pela capacidade de posse e manutenção dos diferentes tipos de capitais disponíveis (econômico, 
cultural, social...), e exerceria uma espécie de dominação sobre as demais classes, determinando, pela exclusividade de capitais específicos, aquilo que é legitimamente reconhecido. Em Freire, a expressão da determinação desse controle de poder das elites seria manifestada, ainda que implicitamente, pela relação de opressão, estabelecendo a existência dos opressores e dos oprimidos.

Tanto em Bourdieu quanto em Freire, o modelo de educação formal existente nesse tipo de organização social seria uma expressão da própria sociedade. Nesse sentido, para Bourdieu, a escola cumpriria um papel de reprodutora da cultura dominante e, por consequência, de mantenedora das desigualdades sociais, já que não reconheceria as diferentes origens culturais e sociais dos educandos, oferecendo a todos o mesmo tipo de educação - da qual a educação das camadas abastadas é mais próxima -, desfavorecendo e excluindo, portanto, os estudantes provenientes dos meios menos favorecidos porque lhes seria estranha a cultura escolar. Já em Freire, observa-se que, ao desconsiderar os conhecimentos prévios dos educandos, impor-lhes o silêncio, negar-lhes a liberdade, e contradizer educadores e educandos, a educação "bancária" estaria a serviço dos opressores, na mesma medida em que estes impedem a existência dos oprimidos, silenciam-nos, roubam-lhes a autonomia, e a eles se opõem.

A reprodução dos mecanismos sociais pela cultura escolar se faria do mesmo modo que a educação "bancária" manteria os educandos em posições fixas. A alienação, de que Freire fala, promovida pelos mecanismos de opressão, seria a forma dissimulada de as instituições escolares promoverem a violência simbólica que Bourdieu explica.

O julgamento moral feito pela escola, sobretudo por meio da figura docente, às habilidades e comportamentos dos estudantes, como apontado por Bourdieu, vai ao encontro da postura do professor da educação "bancária", explicitada por Freire, de julgar que os educandos nada saberiam. A escola desconsideraria os saberes culturalmente herdados pelos educandos em suas vivências familiares e cotidianas quanto mais distantes elas estivessem da cultura dominante, reproduzida pelos sistemas de ensino. Da mesma maneira, mais estranha seria a cultura escolar aos educandos quanto mais aquela desconsiderasse suas origens socioculturais, provocando neles um efeito silenciador, marca da sociedade opressora. 
Bourdieu chegou a cogitar a superação dos processos de reprodução realizados pela escola por meio do que ele mencionou ser uma "pedagogia racional" ou "racionalização da pedagogia", revelando tudo o que fosse implícito na atuação do sistema de ensino, e neutralizando, por intermédio de uma aprendizagem "metódica", seus efeitos de manutenção das desigualdades sociais. Curiosamente, Freire havia pensado em métodos ativos de educação, capazes de conscientizar os sujeitos, por meio do diálogo entre educador e educando, na busca de sua autonomia como povo. Todavia, enquanto o teórico francês acreditou que tal ideia não se trataria de outra coisa que não fosse uma utopia, no Brasil, Freire chegou a criar um método próprio, em busca de uma educação para a liberdade, ao qual ele chamou de "universo temático" ou "temas geradores" do povo. Assim, enquanto Bourdieu acreditava que a educação se manteria uma condição para a reprodução da distinção das elites na sociedade, Freire confiava na capacidade de transformação da "pedagogia do oprimido" em "pedagogia dos homens em processo de permanente libertação".

O debate de ideias sobre a educação que o diálogo entre as teorias de Bourdieu e Freire traz para as práticas educativas reforça, portanto, a necessidade de rompimento com práticas não críticas porque o que elas fazem não é outra coisa senão corroborar as estruturas dominantes e opressoras da sociedade. Promovendo uma educação que, geralmente, faz-se apenas para o mundo do trabalho, as práticas educativas tradicionais não estão a favor da conscientização dos sujeitos, o que é fundamental para a manutenção da organização social injusta existente.

\section{Considerações finais}

A utilização de diferentes práticas educativas teorizadas ao longo do conhecimento pedagógico não traria nenhum mal caso essas práticas se preocupassem, todas elas, em ajudar os educandos a se tornar seres críticos e conscientes da realidade. A verdade, porém, é que, ainda atualmente, a educação, muitas vezes, é colocada "sobre" os estudantes, e não "com" eles, contribuindo para que se mantenha uma distância entre a escola e a realidade de muitos indivíduos, principalmente os menos favorecidos socialmente.

Mediante uma revisão de literatura acerca da teoria crítico-reprodutivista de Pierre Bourdieu e a teoria crítica de Paulo Freire 
para a problemática da educação, este ensaio, ao propor um diálogo entre essas duas visões, observou que a escola atuaria como um meio de reprodução e legitimação das desigualdades sociais, e que, ao se impor sobre os estudantes, ela agiria como um mecanismo próprio das sociedades opressoras. Nessa perspectiva, a correlação entre os fundamentos teóricos dos dois autores mostrou que é preciso que a educação se livre de suas versões mais tradicionais, não críticas, para que exerça seu papel de conscientização dos indivíduos para a transformação social.

Estudos futuros dedicados a compreender mais profundamente as possíveis relações entre as teorias de Bourdieu e Freire para a educação poderiam indicar novas análises que contribuam para o avanço de reflexões sobre as teorias críticas de educação, assim como para a introdução de práticas educativas que se motivem a partir delas.

\title{
Pierre Bourdieu and Paulo Freire: a dialogue for (about) Education
}

\begin{abstract}
The reality of Brazilian education today demonstrates that there is a variety of educational practices put into action in schools, such that they would be a reflection of the various theories already published and experimented throughout pedagogical studies. Pierre Bourdieu, in his theory, demonstrated that education systems would act as mechanisms of reproduction and legitimation of social inequalities. Paulo Freire, in constructing his theory on education, found that the reality of society would be presented in the form of oppression of the peoples, elaborating a method of education for the liberation of the oppressed. In this sense, the objective of this essay was to understand Pierre-Bourdieu's critical-reproductive theory and Paulo Freire's critical theory, in order to think about how the dialogue between them could contribute to educational practices. The methodology was carried out by reviewing the literature on these theories, and analyzing the information observed from them. It is, therefore, a bibliographic study of qualitative object. The analysis of the essay noted that the school would act as a means of reproducing and legitimizing social inequalities, and that by acting on students it would act as a mechanism of oppressive societies. In this perspective, the correlation between the theoretical foundations of the two authors revealed that it is necessary to break with traditional and non-critical educational practices, which reinforce and thus act for the maintenance of an unequal society as it presents itself.
\end{abstract}

Keywords: Social differences. Liberating Pedagogy. Society and Education. 


\section{Pierre Bourdieu y Paulo Freire: un diálogo para (mediante) la Educación}

RESUMEN: La realidad de la educación brasileña actualmente demuestra que existe una variedad de prácticas educativas colocadas en acción en las escuelas, tales que serían un reflejo de las varias teorías ya publicadas y experimentadas a lo largo de los estudios pedagógicos. Pierre Bourdieu, en su teoría, demostró que los sistemas de enseñanza actuarían como mecanismos de reproducción y legitimación de las desigualdades sociales. Paulo Freire, al construir su teoría sobre la educación, constató que la realidad de la sociedad se presentaría en la forma de opresión de los pueblos, elaborando un método de educación para la liberación de los oprimidos. En este sentido, el objetivo de este ensayo fue comprender la teoría crítico-reprodutivista de Pierre Bourdieu y la teoría crítica de Paulo Freire, a fin de que se pensara de qué forma el diálogo entre ambas podría contribuir con las prácticas educativas. La metodología ocurrió por medio de la revisión de literatura sobre esas teorías, y del análisis de las informaciones observadas a partir de ellas. Se trata, así, de un estudio bibliográfico de objeto cualitativo. Los análisis del ensayo observaron que la escuela actuaría como un medio de reproducción y legitimación de las desigualdades sociales, y que, al imponerse sobre los estudiantes, actuaría como un mecanismo propio de las sociedades opresoras. En esta perspectiva, la correlación entre los fundamentos teóricos de los dos autores reveló que hay que romper con las prácticas educativas tradicionales y no críticas, las cuales refuerzan y, de ese modo, actúan para el mantenimiento de la sociedad desigual tal cual se presenta.

Palabras clave: Desigualdades sociales. Pedagogía Libertadora. Sociedad y Educación.

\section{Referências}

BOURDIEU, P. A escola conservadora: as desigualdades frente à escola e à cultura. In: BOURDIEU, P. Escritos de educação. Seleção, organização, introdução e notas: Maria Alice Nogueira e Afrânio Catani. 16. ed. Petrópolis: Vozes, 2015a. p. 43-72. (Coleção Ciências Sociais da Educação).

BOURDIEU, P. O capital social: notas provisórias. In: BOURDIEU, P. Escritos de educação. Seleção, organização, introdução e notas: Maria Alice Nogueira e Afrânio Catani. 16. ed. Petrópolis: Vozes, 2015b. p. 73 78. (Coleção Ciências Sociais da Educação).

BOURDIEU, P. Os três estados do capital cultural. In: BOURDIEU, P. Escritos de educação. Seleção, organização, introdução e notas: Maria Alice Nogueira e Afrânio Catani. 16. ed. Petrópolis: Vozes, 2015c. p. 7988. (Coleção Ciências Sociais da Educação).

FREIRE, P. Educação como prática da liberdade. Rio de Janeiro: Paz e Terra, 1967.

FREIRE, P. Pedagogia do oprimido. 66. ed. Rio de Janeiro: Paz e Terra, 2018. 
LIMA, T. C. S. de; MIOTO, R. C. T. Procedimentos metodológicos na construção do conhecimento científico: a pesquisa bibliográfica. Revista Katálysis, Florianópolis, v. 10, n. esp., p. 37-45, 2007.

NOGUEIRA, M. A.; NOGUEIRA, C. M. M. Bourdieu \& a Educação. 4. ed. Belo Horizonte: Autêntica Editora, 2016. (Coleção Pensadores \& Educação).

SUHR, I. R. F. Teoria do conhecimento pedagógico. Curitiba: InterSaberes, 2012. (Série Fundamentos da Educação).

WACQUANT, L. Habitus. In: CATANI, A. M. et al. (org.). Vocabulário Bourdieu. Belo Horizonte: Autêntica Editora, 2017. p. 213-217.

Submetido em: 27/05/2019

Aceito em: $23 / 07 / 2020$ 